\title{
Enteroscopy in Crohn's Disease: Are There Any Changes in Role or Outcomes Over Time? A KASID Multicenter Study
}

\author{
Seong Ran Jeon ${ }^{1}$, Jin-Oh Kim¹, Jeong-Sik Byeon², Dong-Hoon Yang², Bong Min Ko³, Hyeon Jeong Goong ${ }^{3}$, Hyun \\ Joo Jang ${ }^{4}$, Soo Jung Park ${ }^{5}$, Eun Ran Kim${ }^{6}$, Sung Noh Hong ${ }^{6}$, Jong Pil Im , Seong-Eun Kim ${ }^{8}$, Ja Seol Koo', Chang \\ Soo Eun ${ }^{10}$, and Dong Kyung Chang ${ }^{6}$, Small Intestine Research Group of the Korean Association for the Study of \\ Intestinal Diseases (KASID) \\ ${ }^{1}$ Department of Internal Medicine, Soonchunhyang University College of Medicine, ${ }^{2}$ Department of Internal Medicine, University of \\ Ulsan College of Medicine, Seoul, ${ }^{3}$ Department of Internal Medicine, Soonchunhyang University College of Medicine, Bucheon, \\ ${ }^{4}$ Department of Internal Medicine, Hallym University College of Medicine, Hwaseong, ${ }^{5}$ Department of Internal Medicine, Yonsei \\ University College of Medicine, ${ }^{6}$ Department of Internal Medicine, Sungkyunkwan University School of Medicine, ${ }^{7}$ Department of \\ Internal Medicine, Seoul National University College of Medicine and Liver Research Institute, ${ }^{8}$ Department of Internal Medicine, Ewha \\ Womans University College of Medicine, Seoul, 9Department of Internal Medicine, Korea University College of Medicine, Ansan, and \\ ${ }^{10}$ Department of Internal Medicine, Hanyang University College of Medicine, Guri, Korea
}

See editorial on page 325 .

\section{Article Info}

Received January 15, 2020

Revised April 17, 2020

Accepted April 29, 2020

Published online July 6, 2020

\section{Corresponding Author}

Dong Kyung Chang

ORCID https://orcid.org/0000-0001-8925-4629

E-mail dkchang@skku.edu
Background/Aims: Although balloon-assisted enteroscopy (BAE) enables endoscopic visualization of small bowel (SB) involvement in Crohn's disease (CD), there is no data on the changes in outcomes over time. We therefore investigated the changes in BAE use on CD patients over different time periods in terms of its role and clinical outcomes.

Methods: We used a multicenter enteroscopy database to identify CD patients with SB involvement who underwent BAE (131 procedures, 116 patients). We compared BAE-related factors and outcomes between the first period (70 procedures, 60 patients) and the second period (61 procedures, 56 patients). The specific cutoff point for dividing the two periods was 2007 , when BAE guidelines were introduced.

Results: Initial diagnosis of SB involvement in $C D$ was the most common indication for BAE during each period $(50.0 \%$ vs $31.1 \%, p=0.034)$. The largest change was in the number of $B A E$ uses for stricture evaluation and/or treatment, which increased significantly in the latter period ( $2.9 \%$ vs $21.3 \%, p=0.002$ ). The diagnostic yield in patients with suspected CD was $90.7 \%$ in the first period and $95.0 \%$ in the second $(p=0.695)$. More endoscopic interventions were performed in the second period than in the first $(5.1 \%$ vs $17.6 \%, p=0.041)$. Enteroscopic success rates were high throughout (100\% in the first period vs $80.0 \%$ in the second period, $p>0.999$ ). In the first and second periods, therapeutic plans were adjusted in $62.7 \%$ and $61.4 \%$ of patients, respectively.

Conclusions: The overall clinical indications, outcomes, and effectiveness of BAE were constant over time in CD patients with SB involvement, with the exception that the frequency of enteroscopic intervention increased remarkably. (Gut Liver 2021;15:375-382)

Key Words: Balloon-assisted enteroscopy; Crohn disease; Small bowel; Time; Outcome

\section{INTRODUCTION}

The incidence and prevalence of inflammatory bowel disease, including Crohn's disease (CD) and ulcerative colitis, has been increasing in Asian countries..$^{1-3} \mathrm{CD}$ is a chronic inflammatory bowel disease characterized by its relapsing course and its involvement of the entire gastrointestinal tract. Although small bowel (SB) involvement is common in patients with $\mathrm{CD}$, it is relatively difficult to access with conventional endoscopy. ${ }^{4}$ The introduction of balloon-assisted enteroscopy (BAE) and of capsule endoscopy (CE) have drastically changed the diagnostic 
approach and therapeutic decision making of $\mathrm{CD}$ with $\mathrm{SB}$ involvement. The role of $\mathrm{CE}$ includes ensuring early diagnosis of CD with SB involvement, making differential diagnoses, evaluating unexplained symptoms, extent of inflammation, disease activity and mucosal healing, or recurrence in CD patients. ${ }^{5-8}$ Unlike CE, BAE can be performed on patients with stenosis of the SB and further aids in differential diagnosis by obtaining tissue specimen. ${ }^{9,10}$

According to a study on double-balloon enteroscopy (DBE) in suspected CD (sCD) cases, SB involvement was found in $60 \%$ and therapeutic adjustments were initiated in $75 \%$ of patients. ${ }^{11}$ Another study of CD patients with strictures reported that the technical success rate was $80 \%$ with the avoidance of surgery rate of $60 \%$. The authors therefore suggested that DBE was an effective diagnostic and therapeutic method in patients with CD-associated SB strictures. ${ }^{12}$

However, these studies have only focused on diagnostic yield, therapeutic result or technical aspects for relatively short periods. There has been no studies evaluating these parameters over long periods of time. We aim to evaluate the influence of cumulated knowledge and experience on BAE-related outcomes in CD patients with SB involvement. Therefore, our study investigated the changes in the indications and clinical outcomes of BAE use between different time periods.

\section{MATERIALS AND METHODS}

\section{Study design and patients}

We retrospectively analyzed the records from the enteroscopy multicenter database of CD patients with SB involvement who underwent BAE between January 2004 and February 2013. Patients who had medication histories such as nonsteroidal anti-inflammatory drugs, anticoagulant, or antiplatelet agent use were excluded. From 1,057 procedures (on 990 patients), a total of 131 (116 patients) met the inclusion criteria and were enrolled in this study. We then categorized them into two periods, the first (January 2004 to December 2007) and the second (January 2008 to February 2013). Only one of the enrolled patients received BAE in both time periods. The specific cutoff point was chosen with the assumption that more knowledge and experience of BAE would have been accumulated during the second time point after the introduction of BAE guidelines in $2008 .{ }^{13}$ Data collection and analysis were approved by the institutional review board of each facility. Due to the retrospective nature of this study, patients' informed consent to participate was waived in accordance with the institutional review board. All authors had access to the study data and had reviewed and approved the final manuscript.

\section{BAE procedure}

Procedures were performed using the commercially available DBE system (EN450P5/20, T5/20; Fujinon Inc, Saitama, Japan) or the single-balloon enteroscopy system (Olympus Optical Co., Ltd., Tokyo, Japan). For BAE with an oral approach, patients received nil-by-mouth for at least 8 hours before the procedure. For BAE with an anal approach, patients were prepared for colonoscopy using at least $2 \mathrm{~L}$ polyethylene glycol-electrolyte lavage solution the day before the procedure, which was the accepted protocol at that time. BAE procedures were performed on patients under monitored anesthesia care with a fluoroscopy unit. All BAE procedures were performed under sedation administered by the endoscopists following the sedation protocol of each center. The procedures were divided into expert and non-expert groups based on the endoscopists' learning curve, where a cutoff was defined as 30 cases based on previous study. ${ }^{14}$

\section{Definitions}

Diagnosis of CD was confirmed based on clinical symptoms and a combination of endoscopic, histological, radiological, and/or biochemical investigations. ${ }^{15}$ Early $\mathrm{CD}$ was defined as a disease duration of less than 2 years. ${ }^{16}$ Phenotypes were classified according to the Montreal classification. ${ }^{17}$ Disease location was classified into four groups: (1) L1 (ileal), (2) L2 (colonic), (3) L3 (ileocolonic), and (4) L4 (isolated upper disease). Disease behavior was classified into three groups: (1) B1 (non-stricturing, nonpenetrating), (2) B2 (stricturing), and (3) B3 (penetrating). Extent of $\mathrm{CD}$ was classified into extensive (CD affecting a $>100 \mathrm{~cm}$ area irrespective of the location) and localized (CD affecting a $<30 \mathrm{~cm}$ area). ${ }^{15}$ The endoscopic activity of CD was graded as follows: (1) grade 0 (no activity: normal villous pattern); (2) grade 1 (mild activity: mucosal edema and erythema, and/or presence of small ulcerative lesions in combination with normal mucosa); (3) grade 2 (moderate activity: presence of larger ulcerative lesions in combination with normal mucosa); (4) grade 3 (severe activity: presence of larger ulcerative lesions with absence of normal mucosa); (5) grade 4 (strictures with or without activity of $\mathrm{CD}$, to be or not to be passed by the endoscope). ${ }^{11}$

\section{Measurement factors}

We evaluated the changes of indications, enteroscopic findings, diagnostic yield, treatment, and clinical impact over the indicated study period. Indications for BAE were classified into seven groups, as adopted from a previous study: ${ }^{18}$ (1) initial diagnosis, (2) evaluation of cause for 
obscure gastrointestinal bleeding (OGIB), (3) differential diagnosis, (4) evaluation and/or treatment of strictures, (5) evaluation of disease extent or activity, (6) to identify complications or malignancy, and (7) evaluation of postoperative recurrence. Initial diagnosis was defined as performance of BAE in SCD patients based on guidelines. ${ }^{13} \mathrm{OGIB}$ was defined as recurrent and persistent visible bleeding or anemia from an unknown origin that fail to be identified with upper and lower endoscopy. Although OGIB as initial presentation of $\mathrm{CD}$ without other gastrointestinal symptoms is uncommon, it could not be negligible. Therefore, we analyzed OGIB separately as indications of BAE. Differential diagnosis was defined as BAE use to differentiate $\mathrm{CD}$ when tuberculosis or other inflammatory diseases were concurrently observed in other examination findings prior to BAE. The enteroscopic finding most commonly used to diagnose $\mathrm{CD}$ is the presence of more than three ulcerations in the absence of nonsteroidal anti-inflammatory drugs, or aphthae or erosive lesions $(>10)$ with continuous or segment-like distribution, or circumferential ulceration and stenosis on BAE. ${ }^{19,20}$ Enteroscopic findings included in our study were as follows: (1) longitudinal ulcer, (2) aphthous ulcer, (3) variable ulcer, (4) cobblestone appear- ance, (5) stricture, (6) inflammatory polyp, (7) scar change, and (8) fistula. The diagnostic yield was defined based on enteroscopic findings of $\mathrm{sCD}$ patients. As previously mentioned, all these factors were compared between the first and second periods of the study.

\section{Statistical analysis}

Statistical analyses were performed using SPSS version 18.0 (SPSS Inc, Chicago, IL, USA). All continuous variables were compared using a two-tailed Student $\mathrm{t}$-test. All categorical variables were compared using Fisher exact test. A p-value of $<0.05$ was used as the cutoff for statistical significance.

\section{RESULTS}

\section{Baseline characteristics}

A total of 131 procedures (on 116 patients) were divided based on the two periods, with 70 procedures (on 60 patients) in the first period and 61 procedures (on $56 \mathrm{pa}$ tients) in the second period. The mean age of patients was 36.4 years and $81 \%$ were male. There were no significant

Table 1. Baseline Characteristics

\begin{tabular}{|c|c|c|c|c|}
\hline Variable & All & First period & Second period & $\mathrm{p}$-value \\
\hline No. patients/No. procedure & 116/131 & $60 / 70$ & $56 / 61$ & \\
\hline Age, yr & $36.4 \pm 14.4$ & $34.7 \pm 11.9$ & $38.3 \pm 16.7$ & 0.176 \\
\hline Male sex & $94(81.0)$ & $47(79.7)$ & 47 (82.5) & 0.814 \\
\hline Disease duration & & & & 0.012 \\
\hline$<2 \mathrm{yr}$ & 119 (90.8) & $68(97.1)$ & $51(83.6)$ & \\
\hline$\geq 2 \mathrm{yr}$ & $12(9.2)$ & $2(2.9)$ & $10(16.4)$ & \\
\hline History of abdominal surgery & $18(15.5)$ & $9(15.3)$ & $9(15.8)$ & 0.937 \\
\hline Medication at BAE & & & & 0.384 \\
\hline No & 40 (32.5) & $22(34.4)$ & 18 (30.5) & \\
\hline 5-ASA & 38 (30.9) & $23(35.9)$ & $15(25.4)$ & \\
\hline Steroid & $2(1.6)$ & $1(1.6)$ & $1(1.7)$ & \\
\hline Thiopurine & $2(1.6)$ & $2(3.1)$ & 0 & \\
\hline Biologics & $2(1.6)$ & 0 & $2(3.4)$ & \\
\hline 5-ASA+thiopurine & $17(13.8)$ & $9(14.1)$ & $8(13.6)$ & \\
\hline 5-ASA+steroid & $14(11.4)$ & $4(6.3)$ & $10(16.9)$ & \\
\hline 5-ASA+thiopurine+steroid & $7(5.7)$ & $3(4.7)$ & $4(6.8)$ & \\
\hline 5-ASA+thiopurine+steroid+biologics & $1(0.8)$ & 0 & $1(1.7)$ & \\
\hline \multicolumn{5}{|l|}{ Laboratory test } \\
\hline Hemoglobin, mg/dL & $11.4 \pm 2.5$ & $11.2 \pm 2.3$ & $11.6 \pm 2.8$ & 0.418 \\
\hline $\mathrm{ESR}, \mathrm{mm} / \mathrm{hr}$ & $24.5 \pm 23.0$ & $18.9 \pm 30.1$ & $30.1 \pm 28.6$ & 0.026 \\
\hline $\mathrm{CRP}, \mathrm{mg} / \mathrm{dL}$ & $4.6 \pm 15.5$ & $1.9 \pm 5.9$ & $7.0 \pm 20.3$ & 0.118 \\
\hline Albumin, $\mathrm{mg} / \mathrm{dL}$ & $3.6 \pm 0.7$ & $3.5 \pm 0.8$ & $3.6 \pm 0.6$ & 0.322 \\
\hline \multicolumn{5}{|l|}{ Diagnosis by other modalities } \\
\hline Capsule endoscopy & $21 / 22$ (95.5) & $7 / 7(100)$ & $14 / 15(93.9)$ & 0.523 \\
\hline Abdominal CT & $65 / 99(65.7)$ & $28 / 49(57.1)$ & $37 / 50(74.0)$ & 0.164 \\
\hline SBFT & 49/68 (72.1) & $31 / 43(72.1)$ & $18 / 25(72.0)$ & 0.774 \\
\hline
\end{tabular}

Data are presented as mean \pm SD or number $(\%)$.

BAE, balloon-assisted enteroscopy; ASA, aminosalicylic acid; ESR, erythrocyte sedimentation rate; CRP, C-reactive protein; CT, computed tomography; SBFT, small bowel follow through. 
differences with regards to age and sex between patients of both periods. In the first period, patients with the disease of $<2$ years were of a significantly higher percentage than those in the second period (97.1\% vs $83.6 \%, \mathrm{p}=0.012$ ). No significant differences were observed with regards to history of abdominal surgery or medication. However, the rate of patients who received biologics was very small (3/116) because a high proportion of patients were at early CD (90.8\%) and also restricted by health insurance policy during the study period. ${ }^{21}$ Mean erythrocyte sedimentation rate was statistically higher in the second period than in the first period $(18.9 \pm 30.1 \mathrm{~mm} / \mathrm{hr}$ vs $30.1 \pm 28.6 \mathrm{~mm} / \mathrm{hr}$, $\mathrm{p}=0.026$ ). Among patients who underwent other modalities including $\mathrm{CE}$, abdominal computed tomography or SB follow-through, diagnostic yield was not statistically different. Table 1 summarizes the baseline characteristics of patients undergoing BAE.

\section{Indications and procedure-related data}

Initial diagnosis of $\mathrm{SB}$ involvement of $\mathrm{CD}$ was the most common indication for BAE during each period ( $50.0 \%$ vs $31.1 \%, p=0.034$ ), followed by evaluation of cause for OGIB and evaluation and/or treatment of strictures. Evaluation and/or treatment of strictures increased significantly in the second period as compared with the first (2.9\% vs $21.3 \%$, $\mathrm{p}=0.002$ ) (Fig. 1). Almost all procedures used DBE in both periods. No significant differences between periods were observed with regards to endoscopists' experience with BAE, mean total procedure time and time elapsed to deepest point (Table 2). No major complications such as perforation or pancreatitis were observed.

\section{Enteroscopic findings and diagnostic yield}

Throughout the study period, the locations of $\mathrm{CD}$ were as follows: $\mathrm{L} 4$ (71.6\%), $\mathrm{L} 1+\mathrm{L} 4$ (17.2\%), L2+L4 (8.6\%), and $\mathrm{L} 3+\mathrm{L} 4(2.6 \%)$. The occurrence of CD activity of grades 1 , 2 , 3, and 4 were $37.3 \%, 50.0 \%, 0 \%$, and $15.5 \%$, respectively. The most common disease behavior was B1 (55.2\%) and extended CD was detected in $81.9 \%$ of cases. CD location, activity, behavior and extent were not significantly

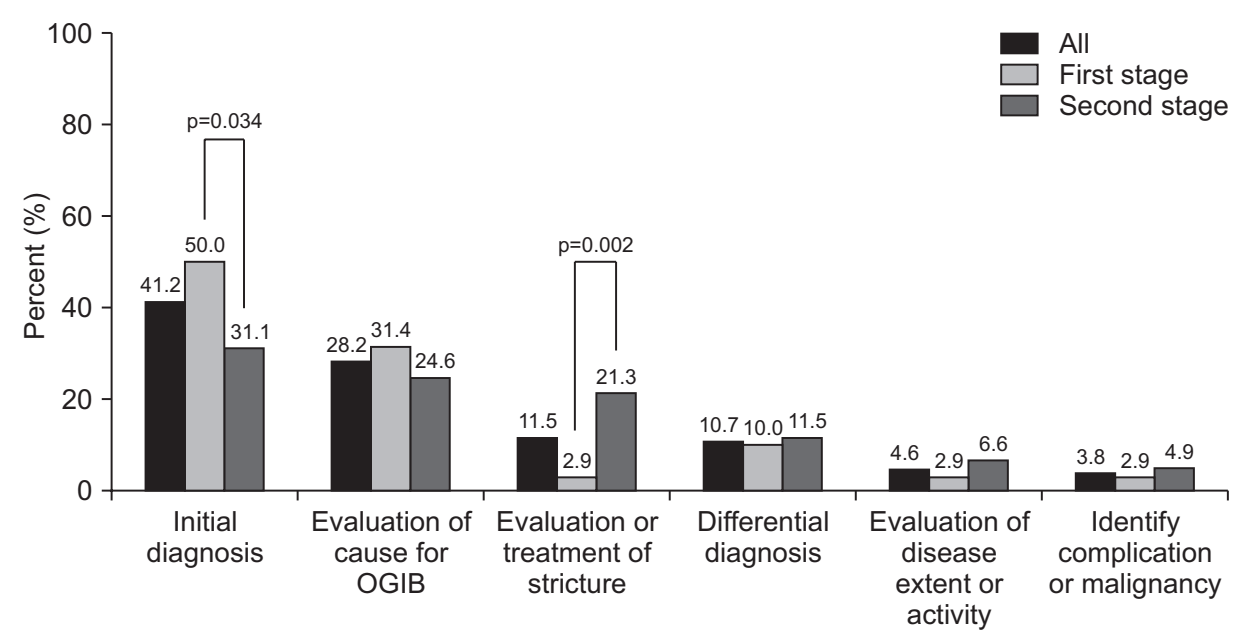

Fig. 1. Balloon-assisted enteroscopy (BAE) indications. Initial diagnosis was the most common indication for BAE during each period $(50.0 \%$ vs $31.1 \%, p=0.034)$, followed by evaluation of the cause of obscure gastrointestinal bleeding (OGIB) and evaluation and/or treatment of strictures. Evaluation and/or treatment of strictures as an indication was significantly more common in the second period than in the first $(2.9 \%$ vs $21.3 \%, p=0.002$ ).

Table 2. Balloon-Assisted Enteroscopy Related Data

\begin{tabular}{|c|c|c|c|c|}
\hline Variable & All & First period & Second period & $\mathrm{p}$-value \\
\hline Type of enteroscopy & & & & 0.098 \\
\hline DBE & $128(97.7)$ & $70(100)$ & $58(95.1)$ & \\
\hline SBE & 3 (2.3) & 0 & $3(4.9)$ & \\
\hline Experience of BAE & & & & 0.144 \\
\hline Expert ( $\geq 30$ procedures) & $101(77.1)$ & $50(71.4)$ & $51(83.6)$ & \\
\hline Non-expert (<30 procedures) & 30 (22.9) & $20(28.6)$ & $10(16.4)$ & \\
\hline Total procedure time (min) & $78.7 \pm 43.7$ & $79.8 \pm 43.9$ & $77.5 \pm 43.9$ & 0.795 \\
\hline Time elapsed to deepest point (min) & $50.2 \pm 31.9$ & $48.9 \pm 22.8$ & $51.6 \pm 40.5$ & 0.727 \\
\hline Route & & & & 0.718 \\
\hline Oral & 50 (38.8) & 25 (36.8) & $25(41.0)$ & \\
\hline Anal & 79 (61.2) & 43 (63.2) & $36(59.0)$ & \\
\hline Major complications & 0 & 0 & 0 & \\
\hline
\end{tabular}

Data are presented as number (\%) or mean \pm SD.

$\mathrm{DBE}$, double-balloon enteroscopy; SBE, single-balloon enteroscopy; BAE, balloon-assisted enteroscopy. 
different between both periods. Longitudinal ulcers were the most common finding for both study periods ( $40.7 \%$ vs $26.3 \%)$, followed by aphthous ulcers ( $23.7 \%$ vs $26.3 \%)$ and strictures (10.2\% vs $12.3 \%)$, but these did not show significant differences (Table 3). The diagnostic yield of BAE obtained by combining the results of other modalities in $\mathrm{SCD}$ patients was $90.7 \%$ in the first period and $95.0 \%$ in the second with no significant differences between both $(\mathrm{p}=0.695)$.

\section{Therapeutic data and clinical impact}

Experience with BAE was not significantly different between both periods. In each, therapeutic data including the number of enteroscopic therapy, enteroscopic success rate and therapeutic plan adjustments were also not significantly different between expert and non-expert groups.

Throughout the study period, $11.2 \%$ (13/116) required endoscopic therapies including balloon dilatation, clipping and CE removal, with the rate of endoscopic therapy performed in the second period being significantly more than that in the first period (5.1\% vs $17.6 \%, \mathrm{p}=0.041)$.
Among them, three patients received additional surgerysegmental resection of SB: two patients continued to have obstructive symptoms which were not relieved after balloon dilatation, and one patient required resection due to $\mathrm{CE}$ retention within a stenotic lesion. Enteroscopic success rate was high throughout the study period ( $100 \%$ vs $80.0 \%$, $\mathrm{p}>0.999$ ). The need for addition of medication was slightly, but insignificantly higher in the first period than in the second $(62.7 \%$ vs $58.7 \%)$, the same goes to the need for therapeutic adjustments (62.7\% and 61.4\%). Table 4 shows the therapeutic data and clinical impact.

\section{DISCUSSION}

The present study is a revisit of our previous study that also looked at the changes of DBE parameters over time. ${ }^{22}$ Previous limitations, such as the single-center and singleoperator approach, were mitigated.

Approximately $10 \%$ to $30 \%$ of CD cases involved solitary SB, ${ }^{15}$ while involvement of both SB and colon

Table 3. Disease Phenotypes and Enteroscopic Findings

\begin{tabular}{|c|c|c|c|c|}
\hline Variable & All & First period & Second period & $\mathrm{p}$-value \\
\hline Location & & & & 0.493 \\
\hline L4 & 83 (71.6) & $39(66.1)$ & 44 (72.2) & \\
\hline $\mathrm{L} 1+\mathrm{L} 4$ & 20 (17.2) & $11(18.6)$ & $9(15.8)$ & \\
\hline $\mathrm{L} 2+\mathrm{L} 4$ & $10(8.6)$ & 7 (11.9) & $3(5.3)$ & \\
\hline$L 3+L 4$ & $3(2.6)$ & $2(3.4)$ & $1(1.8)$ & \\
\hline Behavior & & & & 0.530 \\
\hline B1 & 64 (55.2) & $16(27.1)$ & $21(36.8)$ & \\
\hline B2 & 37 (31.9) & $16(27.1)$ & $21(36.8)$ & \\
\hline B3 & 15 (12.9) & $8(13.6)$ & $7(12.3)$ & \\
\hline Endoscopic activity & & & & 0.516 \\
\hline Grade 1 & 40 (37.3) & 22 (27.3) & $18(31.6)$ & \\
\hline Grade 2 & $58(50.0)$ & $30(50.8)$ & 28 (49.1) & \\
\hline Grade 3 & 0 & 0 & 0 & \\
\hline Grade 4 & 18 (15.5) & 7 (11.9) & 11 (19.3) & \\
\hline Extension & & & & 0.475 \\
\hline Localized & $21(18.1)$ & 9 (15.3) & $12(21.1)$ & \\
\hline Extended & 95 (81.9) & $50(84.7)$ & $45(78.9)$ & \\
\hline Enteroscopic findings & & & & 0.746 \\
\hline Longitudinal ulcer & $39(33.6)$ & $24(40.7)$ & 15 (26.3) & \\
\hline Aphthous ulcer & $29(25.0)$ & 14 (23.7) & 15 (26.3) & \\
\hline Stricture & $13(11.2)$ & $6(10.2)$ & 7 (12.3) & \\
\hline Variable ulcer & 12 (10.3) & $4(6.8)$ & $8(14.0)$ & \\
\hline Longitudinal ulcer+aphthous ulcer & $7(6.0)$ & $3(5.1)$ & $4(7.0)$ & \\
\hline Longitudinal ulcer+cobblestone appearance & $6(5.2)$ & $4(6.8)$ & $2(3.5)$ & \\
\hline Longitudinal ulcer+stricture & $1(0.9)$ & 0 & $1(1.8)$ & \\
\hline Cobblestone appearance & $2(1.7)$ & $1(1.7)$ & $1(1.8)$ & \\
\hline Scar change & $2(1.7)$ & $1(1.7)$ & $1(1.8)$ & \\
\hline Aphthous ulcer+stricture & $1(0.9)$ & 0 & $1(1.8)$ & \\
\hline Aphthous ulcer+cobblestone appearance & $1(0.9)$ & 0 & $1(1.8)$ & \\
\hline Inflammatory polyp+fistula & $1(0.9)$ & $1(1.7)$ & 0 & \\
\hline
\end{tabular}

Data are presented as number (\%). 
Table 4. Therapeutic Data and Clinical Impact

\begin{tabular}{|c|c|c|c|c|}
\hline Variable & All & First period & Second period & $\mathrm{p}$-value \\
\hline Surgery & $6(5.2)$ & $5(8.5)$ & $1(1.8)$ & 0.207 \\
\hline Medical treatment & 97 (83.6) & $51(86.4)$ & $46(80.7)$ & 0.835 \\
\hline Maintain & 38 (39.2) & 19 (37.3) & 19 (41.3) & \\
\hline Add & 59 (60.8) & 32 (62.7) & 27 (58.7) & \\
\hline Enteroscopic therapy & $13(11.2)$ & $3(5.1)$ & $10(17.6)$ & 0.041 \\
\hline Balloon dilatation & $8(61.5)$ & 1 (33.3) & $7(70.0)$ & \\
\hline Clipping & $2(15.4)$ & 1 (33.3) & $1(10.0)$ & \\
\hline Capsule endoscopy removal & $3(23.1)$ & 1 (33.3) & $2(20.0)$ & \\
\hline Enteroscopic success rate & $11 / 13(84.6)$ & $3 / 3(100.0)$ & $8 / 10(80.0)$ & $>0.999$ \\
\hline Therapeutic plan adjustment & $72 / 116(62.1)$ & $37 / 59(62.7)$ & $35 / 57(61.4)$ & $>0.999$ \\
\hline
\end{tabular}

Data are presented as number (\%).

surpassed this with reports of up to $67 \%$ case. ${ }^{23}$ In a population-based cohort study and a single-center study, SB involvement at diagnosis was associated with stricturing or penetrating complications. ${ }^{24,25}$ It is also relatively difficult to access the SB using conventional endoscopy and insertion through the terminal ileum is not always achieved with colonoscopy. ${ }^{13}$ Therefore, BAE has been preferred in the diagnosis of $\mathrm{CD}$ involving the $\mathrm{SB}$.

In this study, the most common indications for BAE were comparable to those reported in a previous study: diagnosis (43.2\%), OGIB (27.0\%), and stenosis (18.9\%). Interestingly, significantly more patients from the first period than the second had early CD (lasting $<2$ years), although the reason for this is unclear. When BAE was performed, majority of the enrolled patients (81.9\%) was first diagnosed with $\mathrm{CD}$. This implies that $\mathrm{BAE}$, regardless of clinical indication, was more often performed on newlydiagnosed SCD patients rather than on patients with established diagnosis of $\mathrm{CD}$.

To avoid re-operations, assessment of endoscopic activity in the SB is important. According to a previous study, endoscopic recurrence was revealed in majority of postoperative $\mathrm{CD}$ patients. ${ }^{27}$ In another study, lesions on the SB and/or anastomosis sites were detected in $94.7 \%$ of patients 1 year after operation, and biologics were started in a considerable number of patients (73.3\%) based on single-balloon enteroscopy findings. ${ }^{28}$ Although BAE has been indicated to evaluate SB involvement and to establish postoperative therapeutic plans, ${ }^{28}$ no BAE indication for the evaluation of postoperative recurrence was present in our study. This may have implied that BAE is difficult for postoperative use and that our research is limited by insufficient coverage of the study period.

Endoscopic findings and procedure-related data and diagnostic yield, as well as the most common indication, did not change during the entire study period. There is presently no standardized endoscopic criteria for diagnosing $\mathrm{CD}^{29}$ In this study, endoscopic findings varied from typical endoscopic features in CD such as longitudinal ulcers and cobblestone appearances to early or minor findings such as aphthous and small ulcers.

In terms of procedure-related outcomes, there were three cases of capsule retention related to SB strictures. Our results therefore support that BAE is useful in detecting SB involvement without concerns of capsule retention in the $\mathrm{SB}^{30}$

The diagnostic yield of BAE has been reported in 22\% to $70 \%$ of sCD patients. ${ }^{26,31-33}$ Although the diagnostic yield of BAE were not significantly different between both periods, it showed a higher diagnostic yield of $92.6 \%$ than that reported in our previous study. ${ }^{22}$ This is possibly due to the fact that a significant number of SCD patients underwent BAE for biopsy or definite diagnosis based on abnormal findings through other imaging modalities. However, this study showed that evaluation and/or treatment of strictures increased significantly in the second period $(2.9 \%$ vs $21.3 \%, \mathrm{p}=0.002$ ) compared with the first. As a result of this influence, more endoscopic interventions were performed in the second period ( $5.7 \%$ vs $16.4 \%, \mathrm{p}=0.048)$ than in the first.

More endoscopic therapy including balloon dilatation, clipping, and CE removal were performed in the second period than in the first, and this was a statistically significant difference $(5.1 \%$ vs $17.6 \%, p=0.041)$. Enteroscopic success rate was high, achieving more than $80 \%$ throughout the study. This result was comparable to that of DBE reported as $80 \%$ in a previous study of $19 \mathrm{CD}$ patients with 13 strictures. $^{12}$ This study also showed that adjustment of therapeutic plans based on BAE results was initiated in more than $60 \%$ of $C D$ patients with SB involvement This is in line with a multicenter retrospective study that included 98 DBE procedures (81 patients), who reported that DBE influenced therapeutic managements in $79 \%$ of patients. ${ }^{34}$ Although our result was relatively lower than that of the recent study, therapeutic plans in both periods were adjusted in nearly two-thirds of all patients $(62.7 \%$ vs $61.4 \%$, 
$\mathrm{p}>0.999$ ). This suggests that BAE may play an important role in therapeutic decision making such as adjustment of medical treatment, surgical consultation, and endoscopic therapeutic intervention. ${ }^{10}$

This study had several potential limitations. Firstly, we switched from the enteroscopy multicenter database registry to a novel web-based registry by the Small Intestine Research Group of the Korean Association for the Study of Intestinal Diseases in October 2015, and as the records were not merged, our records on patients in the second study period might be incomplete as it has disregarded those from the Small Intestine Research Group. Secondly, there might have been a patient selection bias because only $\mathrm{CD}$ patients who underwent BAE in tertiary referral centers were included. We believed that BAE, being an invasive procedure, would require physicians of expertise who would most likely be based in tertiary centers. Thirdly, although each BAE indications had subtle differences, indications such as initial diagnosis, assessing OGIB and treatment strategy could be overlapped, despite our efforts to analyze them as objectively as possible. Since this study included only $\mathrm{CD}$ patients, percentage of differential diagnosis as an indication could be influenced by patients with other kinds of diseases who received BAE. Lastly, due to the lack of long-term follow-up data, further analysis regarding the clinical outcomes could not be performed. Nevertheless, this study has value by showing the changes in procedure indications and clinical outcomes of BAE on CD patients with SB involvement over time. Based on our results, it is suggested that BAE has not been commonly used for follow-up assessment of CD activity. However, it has been considered a relatively safe and effective therapeutic tool before surgery.

In conclusion, the overall clinical indications, outcomes and usefulness of BAE did not change over time in $\mathrm{CD}$ patients with SB involvement, except for the frequency of enteroscopic interventions which has remarkably increased.

\section{CONFLICTS OF INTEREST}

S.J.P. and J.P.I. are editorial board members of the journal but did not involve in the peer reviewer selection, evaluation, or decision process of this article. No other potential conflicts of interest relevant to this article were reported.

\section{ACKNOWLEDGEMENTS}

This work was supported by Soonchunhyang University Research Fund.

\section{AUTHOR CONTRIBUTIONS}

Conceptualization, critical revision of the manuscript for important intellectual content and study supervision: D.K.C. Drafting of the manuscript, methodology, and statistical analysis: S.R.J. Acquisition of data; analysis and interpretation of data: J.O.K., J.S.B., D.H.Y., B.M.K., H.J.G., H.J.J., S.J.P., E.R.K., S.N.H., J.P.I., S.E.K., J.S.K., C.S.E. Approval of final manuscript: all authors.

\section{ORCID}

Seong Ran Jeon https://orcid.org/0000-0001-6970-9737 Jin-Oh Kim https://orcid.org/0000-0002-1773-8058 Jeong-Sik Byeon https://orcid.org/0000-0002-9793-6379 Dong-Hoon Yang https://orcid.org/0000-0001-7756-2704 Bong Min Ko https://orcid.org/0000-0002-0635-4454 Hyeon Jeong Goong

https://orcid.org/0000-0002-3388-5875

Hyun Joo Jang https://orcid.org/0000-0003-4424-1968 Soo Jung Park https://orcid.org/0000-0003-0699-6809 Eun Ran Kim https://orcid.org/0000-0002-0495-2565 Sung Noh Hong https://orcid.org/0000-0002-4140-3717 Jong Pil Im https://orcid.org/0000-0003-1584-0160 Seong-Eun Kim https://orcid.org/0000-0002-6310-5366 Ja Seol Koo https://orcid.org/0000-0002-1202-075X Chang Soo Eun https://orcid.org/0000-0001-6533-9644 Dong Kyung Chang

https://orcid.org/0000-0001-8925-4629

\section{REFERENCES}

1. Yen HH, Weng MT, Tung CC, et al. Epidemiological trend in inflammatory bowel disease in Taiwan from 2001 to 2015: a nationwide populationbased study. Intest Res 2019;17:54-62.

2. Ooi CJ, Hilmi I, Banerjee R, et al. Best practices on immunomodulators and biologic agents for ulcerative colitis and Crohn's disease in Asia. Intest Res 2019;17:285-310.

3. Malekzadeh MM, Sima A, Alatab S, et al. Iranian Registry of Crohn's and Colitis: study profile of first nation-wide inflammatory bowel disease registry in Middle East. Intest Res 2019;17:330-339.

4. Gerson LB, Fidler JL, Cave DR, Leighton JA. ACG clinical guideline: diagnosis and management of small bowel bleeding. Am J Gastroenterol 2015;110:1265-1287.

5. Papadakis KA. Diagnostic approach to small bowel involvement in inflammatory bowel disease: view of the endoscopist. Dig Dis 2009;27:476-481.

6. Bourreille A, Ignjatovic A, Aabakken L, et al. Role of small- 
bowel endoscopy in the management of patients with inflammatory bowel disease: an international OMED-ECCO consensus. Endoscopy 2009;41:618-637.

7. Lewis BS. Expanding role of capsule endoscopy in inflammatory bowel disease. World J Gastroenterol 2008;14:41374141.

8. Leighton JA, Legnani P, Seidman EG. Role of capsule endoscopy in inflammatory bowel disease: where we are and where we are going. Inflamm Bowel Dis 2007;13:331-337.

9. Kim M, Jang HJ. The role of small bowel endoscopy in small bowel Crohn's disease: when and how? Intest Res 2016;14:211-217.

10. Pokala A, Shen B. Update of endoscopic management of Crohn's disease strictures. Intest Res 2020;18:1-10.

11. Mensink PB, Groenen MJ, van Buuren HR, Kuipers EJ, van der Woude CJ. Double-balloon enteroscopy in Crohn's disease patients suspected of small bowel activity: findings and clinical impact. J Gastroenterol 2009;44:271-276.

12. Pohl J, May A, Nachbar L, Ell C. Diagnostic and therapeutic yield of push-and-pull enteroscopy for symptomatic small bowel Crohn's disease strictures. Eur J Gastroenterol Hepatol 2007;19:529-534.

13. Sidhu R, Sanders DS, Morris AJ, McAlindon ME. Guidelines on small bowel enteroscopy and capsule endoscopy in adults. Gut 2008;57:125-136.

14. Gerson LB, Flodin JT, Miyabayashi K. Balloon-assisted enteroscopy: technology and troubleshooting. Gastrointest Endosc 2008;68:1158-1167.

15. Van Assche G, Dignass A, Panes J, et al. The second European evidence-based consensus on the diagnosis and management of Crohn's disease: definitions and diagnosis. J Crohns Colitis 2010;4:7-27.

16. Peyrin-Biroulet L. Why should we define and target early Crohn's disease? Gastroenterol Hepatol (N Y) 2011;7:324326.

17. Satsangi J, Silverberg MS, Vermeire S, Colombel JF. The Montreal classification of inflammatory bowel disease: controversies, consensus, and implications. Gut 2006;55:749753.

18. Kim Y, Jeon SR, Choi SM, et al. Practice patterns and clinical significance of use of capsule endoscopy in suspected and established Crohn's disease. Intest Res 2017;15:467-474.

19. Gay GJ, Delmotte JS. Enteroscopy in small intestinal inflammatory diseases. Gastrointest Endosc Clin N Am 1999;9:115123.

20. Mehdizadeh S, Chen GC, Barkodar L, et al. Capsule endoscopy in patients with Crohn's disease: diagnostic yield and safety. Gastrointest Endosc 2010;71:121-127.

21. Lee J, Im JP, Han K, et al. Changes in direct healthcare costs before and after the diagnosis of inflammatory bowel disease: a nationwide population-based study. Gut Liver
2020;14:89-99.

22. Jeon SR, Kim JO, Kim HG, et al. Changes over time in indications, diagnostic yield, and clinical effects of double-balloon enteros-copy. Clin Gastroenterol Hepatol 2012;10:11521156.

23. Yang SK, Yun S, Kim JH, et al. Epidemiology of inflammatory bowel disease in the Songpa-Kangdong district, Seoul, Korea, 1986-2005: a KASID study. Inflamm Bowel Dis 2008;14:542-549.

24. Thia KT, Sandborn WJ, Harmsen WS, Zinsmeister AR, Loftus EV Jr. Risk factors associated with progression to intestinal complications of Crohn's disease in a population-based cohort. Gastroenterology 2010;139:1147-1155.

25. Cosnes J, Gower-Rousseau C, Seksik P, Cortot A. Epidemiology and natural history of inflammatory bowel diseases. Gastroenterology 2011;140:1785-1794.

26. Manes G, Imbesi V, Ardizzone S, Cassinotti A, Pallotta S, Porro GB. Use of double-balloon enteroscopy in the management of patients with Crohn's disease: feasibility and diagnostic yield in a high-volume centre for inflammatory bowel disease. Surg Endosc 2009;23:2790-2795.

27. Rutgeerts P, Geboes K, Vantrappen G, Beyls J, Kerremans R, Hiele M. Predictability of the postoperative course of Crohn's disease. Gastroenterology 1990;99:956-963.

28. Naganuma M, Watanabe M, Hibi T. Safety and usefulness of balloon endoscopy in Crohn's disease patients with postoperative ileal lesions. J Crohns Colitis 2011;5:73-74.

29. Maaser C, Sturm A, Vavricka SR, et al. ECCO-ESGAR Guideline for Diagnostic Assessment in IBD Part 1: initial diagnosis, monitoring of known IBD, detection of complications. J Crohns Colitis 2019;13:144-164.

30. Ohmiya N, Arakawa D, Nakamura M, et al. Small-bowel obstruction: diagnostic comparison between double-balloon endoscopy and fluoroscopic enteroclysis, and the outcome of enteroscopic treatment. Gastrointest Endosc 2009;69:84-93.

31. Gay G, Delvaux M. Double balloon enteroscopy in Crohn's disease and related disorders: our experience. Gastrointest Endosc 2007;66(3 Suppl):S82-S90.

32. Heine GD, Hadithi M, Groenen MJ, Kuipers EJ, Jacobs MA, Mulder CJ. Double-balloon enteroscopy: indications, diagnostic yield, and complications in a series of 275 patients with suspected small-bowel disease. Endoscopy 2006;38:4248.

33. Jang HJ, Choi MH, Eun CS, et al. Clinical usefulness of double balloon enteroscopy in suspected Crohn's disease: the KASID multi-center trial. Hepatogastroenterology 2014;61:1292-1296.

34. Rahman A, Ross A, Leighton JA, et al. Double-balloon enteroscopy in Crohn's disease: findings and impact on management in a multicenter retrospective study. Gastrointest Endosc 2015;82:102-107. 